\title{
Turnover of cyclin $\mathrm{E}$ by the ubiquitin-proteasome pathway is regulated by cdk2 binding and cyclin phosphorylation
}

\author{
Bruce E. Clurman, ${ }^{1,2,3}$ Robert J. Sheaff, ${ }^{1}$ Kenneth Thress, ${ }^{1}$ Mark Groudine, ${ }^{1,4,5}$ and James $M$. \\ Roberts $^{1}$ \\ ${ }^{1}$ Divisions of Basic Sciences and ${ }^{2}$ Clinical Research, Fred Hutchinson Cancer Research Center, Seattle, Washington 98104 \\ USA; ${ }^{3}$ Departments of Medicine and ${ }^{4}$ Radiation Oncology, University of Washington, Seattle, Washington 98104 USA
}

\begin{abstract}
Cyclin $E$ is a mammalian $G_{1}$ cyclin that is both required and rate limiting for entry into $S$ phase. The expression of cyclin $E$ is periodic, peaking at the $G_{1}-S$ transition and then decaying as $S$ phase progresses. To understand the mechanisms underlying cyclin $E$ periodicity, we have investigated the regulation of cyclin $E$ degradation. We find that cyclin $\mathrm{E}$ is degraded by the ubiquitin-proteasome system, and that this degradation is regulated by both cdk2 binding and cdk2 catalytic activity. Free cyclin $\mathrm{E}$ is readily ubiquitinated and degraded by the proteasome. Binding to cdk2 protects cyclin $\mathrm{E}$ from ubiquitination, and this protection is reversed by cdk2 activity in a process that involves phosphorylation of cyclin $E$ itself. The data are most consistent with a model in which cdk2 activity initiates cyclin $E$ degradation by promoting the disassembly of cyclin E-cdk2 complexes, followed by the ubiquitination and degradation of free cyclin $E$.
\end{abstract}

[Key Words: Cyclin; cdk; ubiquitin; proteasome]

Received June 7, 1996; accepted July 8, 1996.

Cyclins, in association with their catalytic subunits, the cyclin-dependent kinases (cdks), drive the eukaryotic cell cycle through key transitions by phosphorylating a group of largely unknown substrates. More than 10 mammalian cyclins have been identified to date, and most (but not all) are expressed periodically. Each phase of the cell cycle has a unique profile of cyclin-cdk activity, and these distinct fluctuations in cyclin activity are essential for normal cell-cycle progression. The molecular mechanisms underlying cyclin periodicity involve both transcriptional and post-transcriptional regulation. Many cyclin mRNAs exhibit cell-cycle dependent fluctuations, and in some cases, specific transcription factors have been implicated in controlling this periodicity. For example, cyclin $\mathrm{E}$ is controlled by E2F (DeGregori et al. 1995; Duronio and O'Farrell 1995; Geng et al. 1996), and the Saccharomyces cerevisiae $\mathrm{G}_{1}$ cyclins $\operatorname{cln} 1$ and $\operatorname{cln} 2$ are under the control of Swi4/Swi6 (Nasmyth and Dirick 1991; Ogas et al. 1991).

Another major determinant of cyclin periodicity is protein stability, and this may be regulated by the ubiq-

\footnotetext{
${ }^{5}$ Corresponding author.
}

uitin-proteasome system (for review, see Ciechonover 1994; Deshaies 1995; Hochstrasser 1995; Jentsch and Schlenker 1995). Proteins are degraded by this pathway in a series of enzymatic reactions in which ubiquitin is first charged with ATP by ubiquitin-activating enzyme (E1), and then transferred to substrates by a ubiquitinconjugating enzyme (E2). This transfer may also require the action of a ubiquitin ligase (E3), and multiubiquitinated substrate conjugates are rapidly degraded by the $26 \mathrm{~S}$ proteasome. Ubiquitin-mediated proteolysis is regulated at several levels including E2 selection (at least 12 have been identified in yeast), E3 requirements, and cis-acting substrate sequence elements. Substrate phosphorylation can also regulate proteasomal degradation (e.g., see Chen et al. 1995; Deshaies et al. 1995; Yaglom et al. 1995; Schneider et al. 1996). The ubiquitin-dependent proteolysis of cyclin $B$, which is required for exit from mitosis, has been reconstituted in vitro and requires E1, a specific E2, and a 1500-kD E3 complex termed the anaphase-promoting complex (King et al. 1995; Sudakin et al. 1995). Additionally, the proteolysis of cyclin B (and cyclin A) requires a cyclin amino-terminal destruction box (Glotzer et al. 1991). The yeast cyclins $\operatorname{cln} 2$ and $\operatorname{cln} 3$ are also proteasome substrates, but 
do not contain defined destruction boxes. (Tyers et al 1992; Deshaieset al. 1995; Yaglom et al. 1995/Instead, they contain PEST domains, regions rich in proline, glutamic acid, aspartic acid, and serine that are characteristically found in short-lived proteins (Rogers et al. 1986). Although PEST sequences have been shown to constitute an instability signal that is transferable /Cross and Blake 1993; Barral et al. 1995; Yaglom et al. 1995), the underlying mechanism regulating instability is unknown.

The primary mammalian $G_{1}$ cyclins are the $D$-type cyclins and cyclin E (Sherr 1994). Cyclin E associates with cdk2 and cyclin E-cdk2 activity is both required and rate limiting for $G_{1}$ progression (Ohtsubo and Roberts 1993; Resnitzky et al. 1994; Ohtsubo and Roberts 1995). Cyclin E exhibits periodic expression, peaking at the $\mathrm{G}_{1} / \mathrm{S}$ boundary, and then decaying as $S$ phase progresses (Dulic et al. 1992; Koff et al. 1992). Here we show that cyclin $E$ is degraded by the ubiquitin-proteasome pathway and that this process is regulated by both cdk2 binding and cyclin E-cdk2 catalytic activity. Our data suggest a model in which cdk2-dependent cyclin $\mathrm{E}$ phosphorylation promotes proteasome-dependent cyclin E proteolysis, thus resulting in a negative feedback loop in which cyclin E may catalyze its own destruction.

\section{Results}

Cyclin E is degraded by the ubiquitin-proteasome system

NIH-3T3 cells were transfected with a plasmid containing a CMV promoter driving expression of a mycepitope-tagged human cyclin $\mathrm{E}$ ( $\mathrm{m}$-cyclin $\mathrm{E}$ ), and the transfected cells were treated with the peptide aldehyde LLnL. LLnL inhibits proteasome-mediated proteolysis and leads to the accumulation of proteins that turn over by this pathway (Rock et al. 1994). Because it blocks the degradation of ubiquitinated proteins but does not inhibit the covalent addition of ubiquitin to protein substrates, LLnL treatment also results in the accumulation of polyubiquitin-substrate conjugates. These ubiquitinated intermediates are unstable, and ubiquitin molecules are rapidly cleaved by cellular isopeptidases to yield unconjugated substrate. These isopeptidases are inhibited by n-ethyl maleimide (NEM), and treatment of cells with peptide aldehyde proteasome inhibitors followed by lysis in buffer containing NEM ( $5 \mathrm{~mm}$ ) allows detection of the accumulated unconjugated substrates, as well as the appearance of a characteristic ladder of polyubiquitin-substrate conjugates.

As shown in Figure 1A treatment with LLnL $(50 \mu \mathrm{M})$ resulted in hyperaccumulation of $\mathrm{m}$-cyclin $\mathrm{E}$ protein, as well as a ladder of slower migrating species. Treatment of cells with the calpain inhibitor LLM $(50 \mu \mathrm{m})$, a structurally related peptide aldehyde that does not inhibit the proteasome at this concentration, or dimethylsulfoxide (DMSO; the solvent in which these compounds are dissolved), had no effect on cyclin E protein levels or mobility compared with growth media alone (Fig. 1A, data not shown). To demonstrate that these high molecular weight species contain ubiquitin, an immunoprecipitation-Western assay was used in which an HA-tagged ubiquitin construct was cotransfected with the myctagged cyclin E plasmid (Treier et al. 1994) into NIH-3T3 cells followed by LLnL treatment (Fig. 1B). Extracts were immunoprecipitated with either the anti-HA or 9E10 (anti-myc tag) monoclonal antibodies, followed by Western blotting with either anti-HA or 9E10. High molecular weight species were detected with either antibody and only in cells transfected with both constructs. Thus, these slower migrating species contain both $\mathrm{m}$-cyclin $\mathrm{E}$ and HA-ubiquitin and represent multiubiquitinated forms of m-cyclin E. As previously reported with the c-Jun protein (Treier et al. 1994), the molecular weight distribution of conjugates depends on which antibody is used for immunodetection. Thus, higher molecular weight forms are preferentially detected with anti-HA (following 9E10 immunoprecipitation), presumably because the number of HA-ubiquitin moieties per cyclin $\mathrm{E}$ molecule increases as the molecular weight of the conjugate increases, whereas each conjugate contains only a single cyclin E molecule. To control for any possible effects resulting from the myc epitope tag, untagged human cyclin $E$ was substituted for $m$-cyclin $E$ in these and subsequent experiments and indistinguishable results were obtained (data not shown).

To demonstrate the ubiquitin-dependent turnover of cyclin $E$ in another system, we utilized the ts 20 cell line which carries a temperature-sensitive mutation in E1 (Kulka et al. 1988). At the nonpermissive temperature $\left(40^{\circ} \mathrm{C}\right)$, El cannot activate ubiquitin, and proteins degraded by the ubiquitin-proteasome system are stabilized. Figure $1 \mathrm{C}$ shows that whereas $\mathrm{m}$-cyclin $\mathrm{E}$ significantly hyperaccumulates in ts 20 cells at $40^{\circ} \mathrm{C}$, endogenous cdk2 expression is unaffected by $\mathrm{E} 1$ inactivation at the nonpermissive temperature. Furthermore, cyclin $\mathrm{E}$ expression is not significantly stabilized by the temperature shift in E36 cells, the ts 20 parental cell line that has a normal E1 (data not shown). The hyperaccumulation of $\mathrm{m}$-cyclin $\mathrm{E}$ at the nonpermissive temperature in ts 20 cells implies that it is significantly degraded by the proteasome at $34^{\circ} \mathrm{C}$. To confirm this, ts 20 cells expressing $\mathrm{m}$-cyclin $\mathrm{E}$ were treated with $\mathrm{LLnL}$ (Fig. 1C, lane 2). LLnL treatment resulted in $\mathrm{m}$-cyclin $\mathrm{E}$ hyperaccumulation such that the steady state level was equal to that seen at $40^{\circ} \mathrm{C}$. The observations that $\mathrm{m}$-cyclin $\mathrm{E}$ expression in ts 20 cells was increased by either $E 1$ inactivation or LLnL treatment strongly suggest that $\mathrm{m}$-cyclin $\mathrm{E}$ is degraded by ubiquitin-dependent proteolysis in these cells.

Under the transfection conditions used in these experiments $(1.5 \mu \mathrm{g}$ CS2 m-cyclin E plasmid/60-mm dish), exogenous cyclin $\mathrm{E}$ is in excess of cdk2, as shown by the increased amount of cdk2 that coprecipitates with cyclin E when a cdk2 expression plasmid is cotransfected (Fig. 1D). Thus, the effects of LLnL treatment may largely reflect the turnover of free cyclin $\mathrm{E}$. To investigate this possibility, we used a cyclin $\mathrm{E}$ mutant, m-cyclin $\mathrm{E}(\mathrm{R} 130 \mathrm{~A})$, that does not bind cdk2. (Fig. 2A; Kobayashi et 


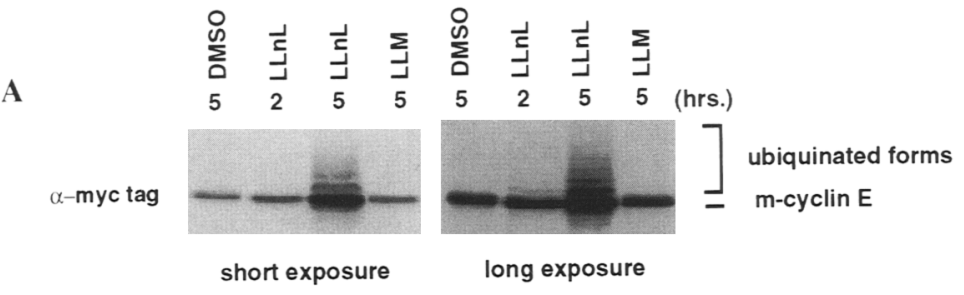

B

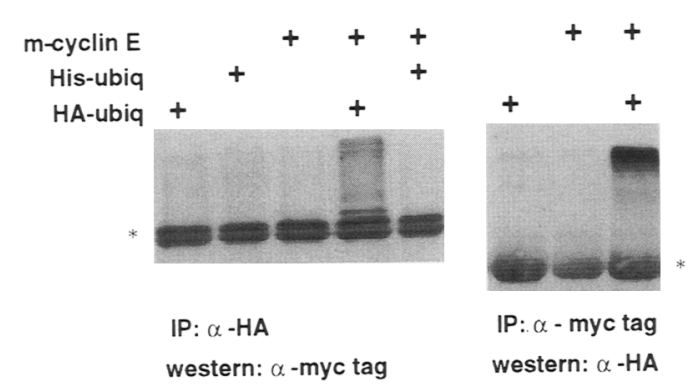

C

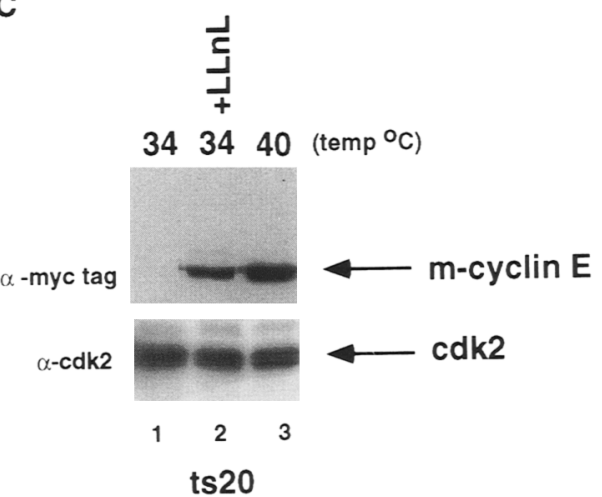

D

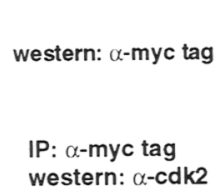
western: $\alpha$-cdk2
Figure 1. Ubiquitination and proteasomal degradation of cyclin E. $(A)$ Proteasome inhibition by $L L n L$ results in cyclin $E$ accumulation and a ladder of higher molecular weight species. After transfection with $\mathrm{m}$-cyclin $\mathrm{E}$, NIH-3T3 cells were treated with the peptide aldehydes LLnL or LLnL $(50 \mu \mathrm{M})$, or no drug. The positions of unconjugated and ubiquitinated forms of $\mathrm{m}$-cyclin $\mathrm{E}$ are indicated. (B) Identification of cyclin E-ubiquitin conjugates by an immunoprecipitation-Western analysis. NIH-3T3 cells were transfected with the indicated plasmids followed by treatment with LLnL. (Left) Cell lysates were immunoprecipitated with anti-HA antibody, followed by Western blotting with $9 \mathrm{E} 10$ as the primary antibody (which recognizes the myc-tag on m-cyclin E). (Right) Cell lysates were immunoprecipitated with $9 \mathrm{E} 10$, and the Western blot was probed with anti-HA. Ubiquitin-cyclin E conjugates are detected only in cells transfected with both epitope-tagged constructs. $\left({ }^{*}\right)$ IgG heavy chain visualized in this analysis. (C) Cyclin E hyperaccumulates in TS20 cells at the nonpermissive temperature. TS20 cells were transfected with $\mathrm{m}$-cyclin $\mathrm{E}$ and grown at $34^{\circ} \mathrm{C}$ (lanes 1,2 ), or shifted to the nonpermissive temperature 12 hr prior to lysis (lane 3). LLnL was added to cells growing at $34^{\circ} \mathrm{C}$ for $12 \mathrm{hr}$ prior to lysis (lane 2). (D) Expression of transfected m-cyclin $E$ exceeds endogenous cdk2. NIH-3T3 cells were transfected with $\mathrm{m}$-cyclin $\mathrm{E}$ and either vector (lane 1), or CMV-wt-cdk2 (lane 2). A large proportion of the exogenous cyclin $E$ is free under these conditions, as shown by the increased amount of cdk2 that coprecipitates with $\mathrm{m}$-cyclin $\mathrm{E}$ after cdk2 levels are increased by expressing exogenous cdk2. al. 1992). LLnL treatment of cells expressing the nonbinding mutant resulted in both hyperaccumulation of cyclin $\mathrm{E}$ and a ladder of slower migrating species. Thus, free cyclin $\mathrm{E}$ is ubiquitinated and degraded by the proteasome, and this proteolysis is inhibited by LLnL.

The proteosomal turnover of cyclin $E$ is inhibited by cdk2 binding

Most cyclin E protein in cells are found in complexes with cdk2 (Koff et al. 1992). To determine if complex formation with cdk2 effects cyclin E proteolysis, a large excess of a catalytically inactive cdk2 mutant (dn-cdk2) was coexpressed with $\mathrm{m}$-cyclin $\mathrm{E}$ to drive cyclin $\mathrm{E}-\mathrm{cdk} 2$ complex formation. The dn-cdk2 binds cyclin E but is unable to bind and hydrolyze ATP /van den Heuval and Harlow 1993), and was used to dissociate the effects of cyclin $\mathrm{E}$ binding to cdk2 from any effects resulting from the catalytic activity of these complexes. Transfected cells were lysed after treatment with LLnL, LLM, or no drug. Expression of dn-cdk2 resulted in hyperaccumulation of coexpressed $\mathrm{m}$-cyclin $\mathrm{E}$ compared with cells transfected with only m-cyclin E (Fig. 2B). Furthermore, dn-cdk2 blocked the appearance of polyubiquitinated cyclin E conjugates following LLnL treatment, and LLnL did not significantly affect the abundance of $\mathrm{m}$-cyclin $\mathrm{E}$ in cells also expressing dn-cdk2. The effect of dn-cdk2 requires complex formation with cyclin $\mathrm{E}$ and does not result simply from general cdk2 inhibition in the cell, because when dn-cdk2 was coexpressed with $\mathrm{m}$-cyclin $\mathrm{E}$ (R130A), which does not bind cdk2, the steady-state level of this nonbinding mutant was not increased /data not shown). Furthermore, following LLnL treatment of cells coexpressing $\mathrm{m}$-cyclin $\mathrm{E}(\mathrm{R} 130 \mathrm{~A})$ and $\mathrm{dn}$-cdk2, the polyubiquitinated cyclin $\mathrm{E}$ ladder was still easily detected, and LLnL treatment resulted in cyclin E hyperaccumulation (Fig. 2). Thus, unbound cyclin $\mathrm{E}$ is degraded by the proteasome, and binding to cdk2 protects it from degradation. 
cdk2 catalytic activity affects the accumulation of cyclin $E$ bound to cdk2

To determine if the accumulation of cyclin $\mathrm{E}$ bound to cdk2 is affected by the catalytic activity of these complexes, $\mathrm{m}$-cyclin $\mathrm{E}$ was coexpressed with either dn-cdk2 or catalytically active cdk2 (wt-cdk2). To reduce the possibility of titrating endogenous proteins required for cdk2 activation, the least amount of exogenous cyclin $\mathrm{E}$ protein that could be reproducibly detected was used in these experiments. Under these conditions, coexpression of wt-cdk2 did not affect the steady-state abundance of $\mathrm{m}$-cyclin $\mathrm{E}$, whereas dn-cdk2 resulted in cyclin $\mathrm{E}$ hyperaccumulation (Fig. 3A). Thus, cyclin E-cdk2 activity may reverse the stabilizing effect of complex assembly.

As a further test of this model, we inhibited the catalytic activity of cyclin E-cdk2 complexes with the cyclin kinase inhibitor (cki) p27 to determine if this also resulted in cyclin E hyperaccumulation. p27 is a promiscuous cki that binds to and inhibits the activity of most cyclin-cdk complexes (Sherr and Roberts 1995). To determine if $\mathrm{p} 27$ stabilized cyclin $\mathrm{E}$ in complex with catalytically active cdk2, p27 was coexpressed with m-cyclin $\mathrm{E}$ and wt-cdk2. Under these conditions, p27 effectively inhibited cyclin E-cdk2 kinase activity (data not shown) and resulted in even greater cyclin $\mathrm{E}$ hyperaccumulation than observed with dn-cdk2 (Fig. 3A). The increased cyclin E levels resulting from p27, as compared with dncdk2, likely reflects the fact that catalytically active complexes between $\mathrm{m}$-cyclin $\mathrm{E}$ and endogenous cdk2 may form when dn-cdk2 is coexpressed, whereas all $\mathrm{m}$-cyclin $\mathrm{E}-\mathrm{cdk} 2$ complexes are inactivated by $\mathrm{p} 27$ overexpression.

The ability of p27 to increase cyclin E levels localized to the amino-terminal 86 amino acids of p27, the minimum domain of $\mathrm{p} 27$ required for cyclin-kinase binding and inhibition (Fig. 3B; Polyak et al. 1994). Whereas cotransfection of $\mathrm{p} 21$ (a related cki) also increased cyclin E levels (but to a lesser extent than p27), p16 expression (a specific cyclin $\mathrm{D} / \mathrm{cdk} 4$-cdk6 inhibitor) did not. Thus, the ability of ckis to increase cyclin $E$ levels correlated with the ability of these molecules to bind to and inhibit cyclin-cdk2 complexes. In contrast to its effect on cyclin E, p27 expression had no effect on the levels of cotransfected myc-tagged cyclin A. (Fig. 3C)

\section{Mutation of a cyclin E-cdk phosphorylation site results in cyclin $E$ hyperaccumulation}

Cyclin E is autophosphorylated in complex with cdk2 (Koff et al. 1991, 1992; Dulic et al. 1992). Thus, the destabilizing effect of cdk2 activity might be mediated by phosphorylating cyclin E itself. There are five minimal cdk consensus sites (serine/proline or threonine/proline) in cyclin E (Fig. 4A; Koff et al. 1991; Lew et al. 1991). Site-directed mutagenesis was used to change the $T$ or $S$ residues in each site to an alanine, and a quintuple mutant was made in which all five sites were mutated, as well as various combined mutants. These mutants were fully functional and indistinguishable from wild-type cyclin $E$ with respect to either catalytic activity, as assayed by either histone $\mathrm{Hl}$ kinase activity (Fig. $4 \mathrm{~B}$ ), or $\mathrm{G}_{1}$ acceleration in a transient fluorescence-activated cell sorting (FACS) assay (data not shown). Under transfection conditions in which exogenous cyclin $\mathrm{E}$ expression exceeds endogenous cdk2 expression, LLnL treatment resulted in both the steady-state accumulation of these mutants as well as ladder formation (Fig. 4C). The proteasomal degradation of unbound cyclin $\mathrm{E}$ is thus unaffected by these mutations. When complex formation with cdk2 was favored, however, one mutation, $(\mathrm{p} 5)$ resulted in cyclin E stabilization (Fig. 4D|. In contrast with wild-type $\mathrm{m}$-cyclin $\mathrm{E}$, which hyperaccumulates only in catalytically inactive complexes, $\mathrm{m}$-cyclin $\mathrm{E}(\mathrm{p} 5)$ expression was equally increased by complex formation with either wt-cdk2 or dn-cdk2. Thus, steady-state levels of $\mathrm{m}$-cyclin $\mathrm{E}(\mathrm{p} 5)$ depend strictly on cdk2 binding, regardless of catalytic activity. None of the other four mutants exhibited this pattern of stabilization (the $\mathrm{p} 4$ mutation is shown as a representative example in Fig. 5D), although the quintuple mutant behaved similarly to m-cyclin $\mathrm{E}(\mathrm{p} 5)$ (data not shown). The p5 site has recently been directly demonstrated to be phosphorylated by cyclin

Figure 2. Complex formation with $\mathrm{cdk} 2$ protects cyclin $\mathrm{E}$ from proteasomal degradation. (A) Ubiquitination of a cyclin $\mathrm{E}$ mutant deficient in cdk2 binding. NIH$3 \mathrm{~T} 3$ cells were transfected with $\mathrm{m}$-cyclin $\mathrm{E}(\mathrm{R} 130 \mathrm{~A})$ and either vector (lanes 1,2) or CMV-dn-cdk2 (lane 3). Transfected cells were treated with either LLM (lane 1) or LLnL (lanes 2,3). (B) Coexpression of catalytically inactive cdk2 blocks cyclin E ubiquitination. NIH-3T3 cells were co-transfected with either m-cyclin E (lanes 1-6), and either vector (lanes 1-3) or CMV-dn-cdk2 (lanes 4-6). Cells were then treated with the proteasome inhibitors LLnL (lanes 2,5), MG-132 (lanes 3-6), or LLM (lanes 1,4).

A

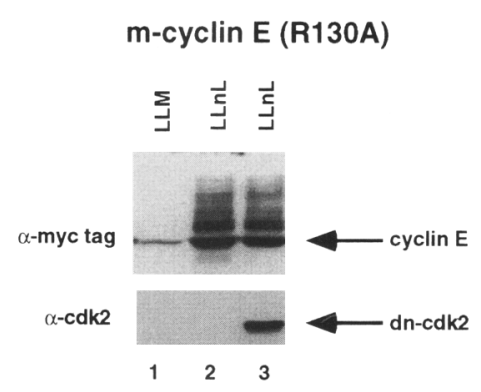

B

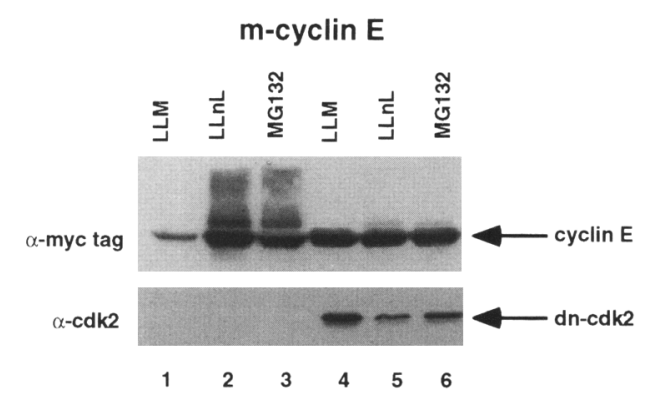


E-cdk2 (Won and Reed 1996). Thus, the accumulation of $\mathrm{m}$-cyclin $\mathrm{E}(\mathrm{p} 5)$ in catalytically active complexes implicates cdk2-mediated phosphorylation at the $\mathrm{p} 5$ site as an important determinant of cyclin E accumulation.

The turnover of cyclin E in catalytically active complexes with cdk2 is proteasome dependent

Assembly of catalytically inactive complexes increases the abundance of cyclin $\mathrm{E}$ in the cell because cyclin $\mathrm{E}$ within this complex is protected from ubiquitin-mediated proteolysis. In contrast, assembly of catalytically active complexes does not increase cyclin $\mathrm{E}$ protein levels. One explanation is that cyclin $\mathrm{E}$ in catalytically active complexes is not protected from degradation by the proteasome. Cells expressing either $\mathrm{m}$-cyclin $\mathrm{E} / \mathrm{wt}$-cdk2 or $\mathrm{m}$-cyclin $\mathrm{E} / \mathrm{dn}$-cdk2 were treated with peptide aldehydes (Fig. 5A). Treatment with LLnL (but not LLM) resulted in cyclin hyperaccumulation when $\mathrm{m}$-cyclin $\mathrm{E}$ was expressed alone or with excess wt-cdk2. However, coexpression of dn-cdk2 increased $\mathrm{m}$-cyclin $\mathrm{E}$ expression to a level similar to that observed after LLnL treatment of $\mathrm{m}$-cyclin E/wt-cdk2 transfected cells. Furthermore, the steady-state level of $\mathrm{m}$-cyclin $\mathrm{E}$ in these catalytically inactive complexes was not increased further by LLnL. The differential sensitivity to LLnL of m-cyclin $E$ in complex with wt-cdk 2 or dn-cdk 2 indicates that m-cyclin $\mathrm{E}$ in catalytically active complexes is degraded by the proteasome, but $\mathrm{m}$-cyclin $\mathrm{E}$ in catalytically inactive complexes is not.

To demonstrate further that the degradation of cyclin $E$ in catalytically active complexes is ubiquitin-dependent, $\mathrm{m}$-cyclin $\mathrm{E}$ was coexpressed with wt-cdk2 in ts 20 cells (Fig. 5B). As observed with free cyclin E, shifting to the non-permissive temperature resulted in significant cyclin E hyperaccumulation, suggesting that the degradation of cyclin $E$ in these complexes is E1-dependent. The proteasome-dependent turnover of cyclin $\mathrm{E}$ in these complexes was confirmed by treatment of cells at both $34^{\circ} \mathrm{C}$ and $40^{\circ} \mathrm{C}$ with $\mathrm{LLnL}$, which resulted in cyclin $\mathrm{E}$
A

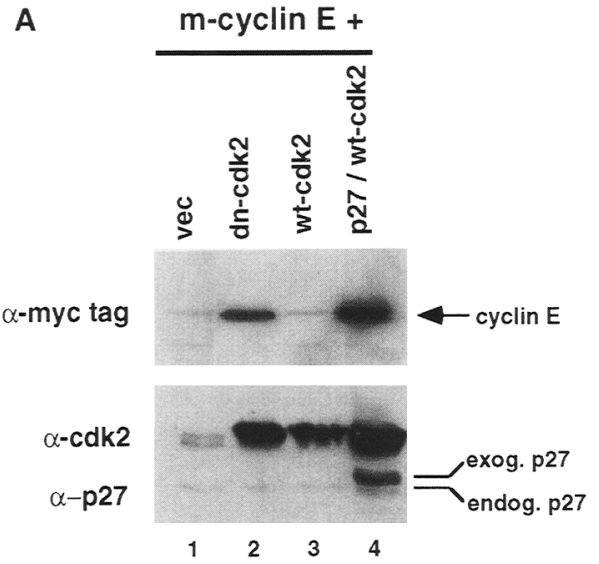

B

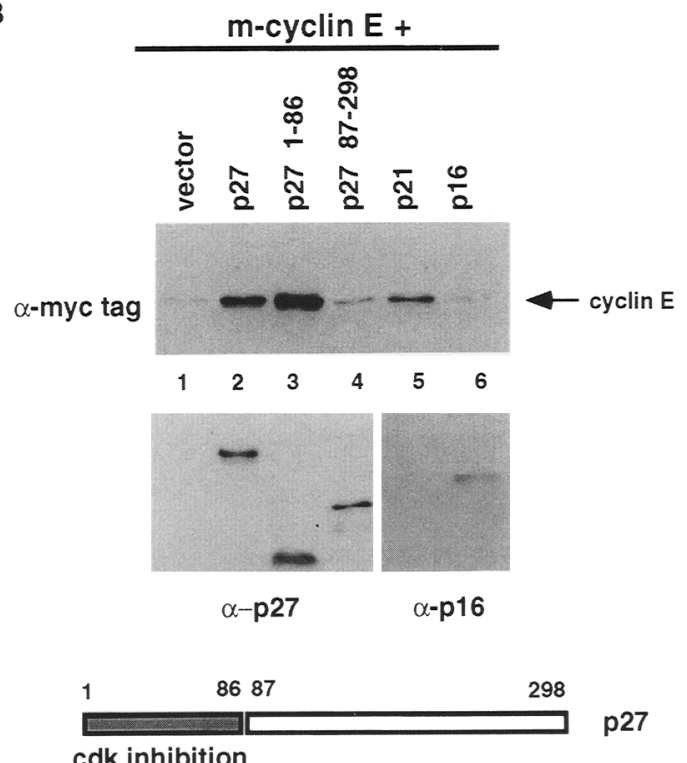

C

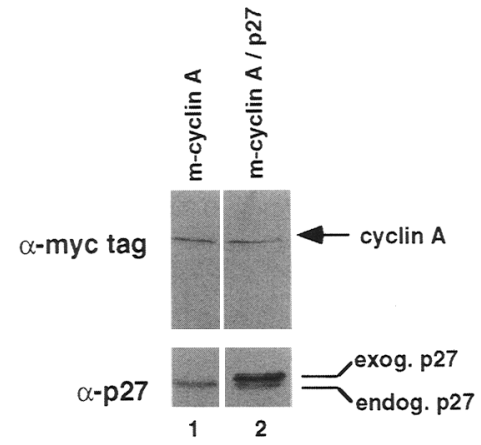

Figure 3. cdk2 activity affects the accumulation of cyclin $\mathrm{E}$ bound to cdk2. $|A|$ cdk2 inhibition leads to cyclin E hyperaccumulation. m-cyclin $\mathrm{E}$ was cotransfected with either vector (lane 1), CMV-dn-cdk2 (lane 2), or CMV-wt-cdk2 (lanes 3,4). In addition, CS2p27 was added to the transfection in lane 4. (Top) Expression of the transfected cyclin E. (Bottom) Blot probed with both $\alpha$-cdk2 and $\alpha$-p27 antibodies. The level of endogenous $\mathrm{cdk} 2$ expression is evident in lane 1 . Because the human p27 protein migrates slightly slower than murine p27, the exogenous and endogenous p27 proteins are easily distinguished from one another as indicated. $(B)$ The amino terminus of p27 is necessary and sufficient for cyclin $E$ hyperaccumulation. The shaded amino terminus in the graphic depiction of $\mathrm{p} 27$ indicates the region of $\mathrm{p} 27$ that is sufficient for cdk inhibition. NIH$3 \mathrm{~T} 3$ cells were cotransfected with $\mathrm{m}$-cyclin $\mathrm{E}$ and either full-length p27 (lane 1), aminoterminal (lane 2), or carboxy-terminal (lane 3) p27 expression vectors. The comparative levels of p27 expression are shown in the lower panel (note the faster migration of the truncated $\mathrm{p} 27$ proteins in lanes 3,4$)$. The cyclin kinase inhibitors p21 (lane 5), or p16 (lane 6) were also cotransfected. (C) Co-expression of p27 does not affect cyclin A expression. NIH-3T3 cells were transfected with a myc-tagged cyclin A construct and either vector (lane 1 ) or CS2p27 (lane 2). 
A

\begin{tabular}{|c|c|c|}
\hline$\Sigma \Sigma$ & $\stackrel{\infty}{a}$ & $\Xi 2$ \\
\hline||$_{\infty} \mid$ & 1 & 11 \\
\hline$\ddot{\circ}$ & $\frac{\infty}{\omega}$ & 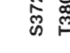 \\
\hline
\end{tabular}

Human Cyclin E
Figure 4. Mutation of threonine 380 confers stability to cyclin $\mathrm{E}$ in complexes with catalytically active cdk2. (A) Cyclin E contains five minimal cdk consensus phosphorylation sites. The location of the five sites conforming to the minimum consensus sequence for cdk2 phosphorylation are indicated $(T$, threonine; $\mathrm{S}$, serine) $(B)$ Mutation of cdk2 consensus sites does not affect cyclin $\mathrm{E}$ kinase activity. NIH-3T3 cells were transfected with constructs expressing the indicated phosphorylation site mutations (lanes 1-8), wild-type $\mathrm{m}$-cyclin $\mathrm{E}$ (lane 9), empty vector (lane 10), or a mutant cyclin $\mathrm{E}$ deficient in cdk2 binding (lane 11). (C) Phosphorylation site mutations do not affect the ubiquitination of unbound cyclin E. NIH-3T3 cells were cotransfected with the indicated $\mathrm{m}$-cyclin $\mathrm{E}$ expression vectors by use of conditions that favor free cyclin E, and the cells were treated with either LLM (odd lanes) or LLnL (even lanes). (D) To examine the effects of phosphorylation site mutations in cyclin E-cdk2 complexes, NIH-3T3 cells were cotransfected with the indicated cyclin $\mathrm{E}$ expression plasmids and either vector (lanes 1,5,9), dn-cdk2 (lanes 2,6,10), or wtcdk2 (lanes 3-4, 7-8, 11-12). CS2p27 was also transfected in lanes 4,8, and 12. (Top) Exogenous cyclin expression; (bottom) Western blots probed with both $\alpha$-CDK2 and $\alpha$-p27.

hyperaccumulation at $34^{\circ} \mathrm{C}$ but did not further increase the already highly elevated levels of cyclin $\mathrm{E}$ at $40^{\circ} \mathrm{C}$.

\section{p27 inhibits the ubiquitination and degradation of cyclin $E$}

One explanation for the failure of LLnL to increase the steady-state levels of cyclin $\mathrm{E}$ in catalytically inactive
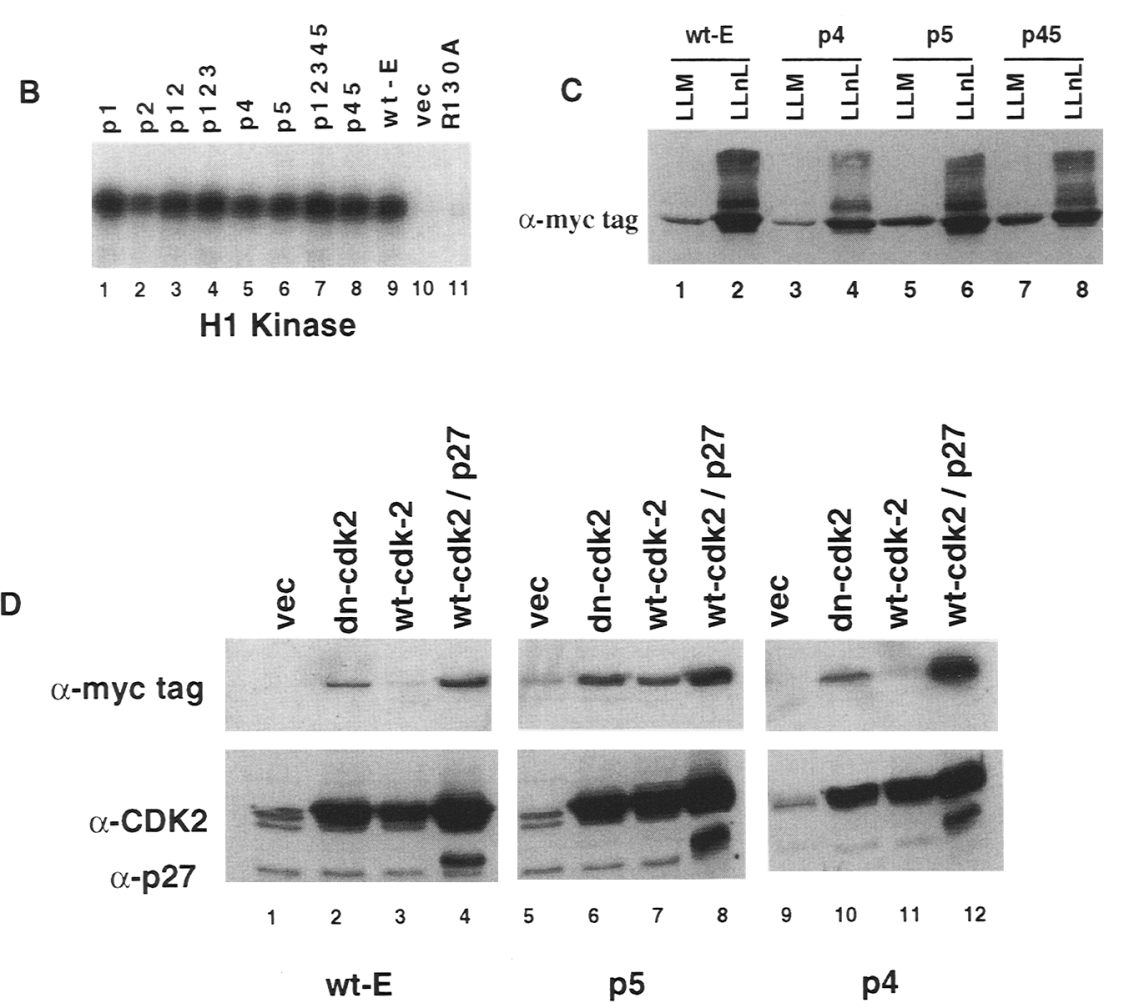

complexes is that cdk2 inhibition blocks cyclin E ubiquitination. To test this, cells transfected with $\mathrm{m}$-cyclin E, p27, and HA-ubiquitin were treated with MG132, LLM, or DMSO (Fig. 6A). A high molecular weight ladder was observed only in cells treated with the proteasome inhibitor MG-132. This ladder was shown to be comprised of ubiquitin-cyclin E conjugates by an immuno-

Figure 5. Proteasome-dependent accumulation of cyclin $\mathrm{E}$ bound to catalytically active cdk2. (A) The proteasomal degradation of cyclin $\mathrm{E}$ bound to cdk2 is regulated by cdk 2 catalytic activity. NIH$3 \mathrm{~T} 3$ cells were cotransfected with CS2mcyclin and either wt-cdk2 (lanes 1,2), vector (lanes 3,4), or dn-cdk2 (lanes 5,6). Cells were then treated with either LLnL (odd lanes), or LLM (even lanes). In this experiment, the ladder of ubiquitinated intermediates is not evident. (B) TS20 cells were cotransfected with $\mathrm{m}$-cyclin $\mathrm{E}$ and excess wt-cdk2. Plates were shifted to the nonpermissive temperature for $12 \mathrm{hr}$ prior to lysis. LLnL was added (lanes 1,3) 2 $\mathrm{hr}$ after the temperature shift.

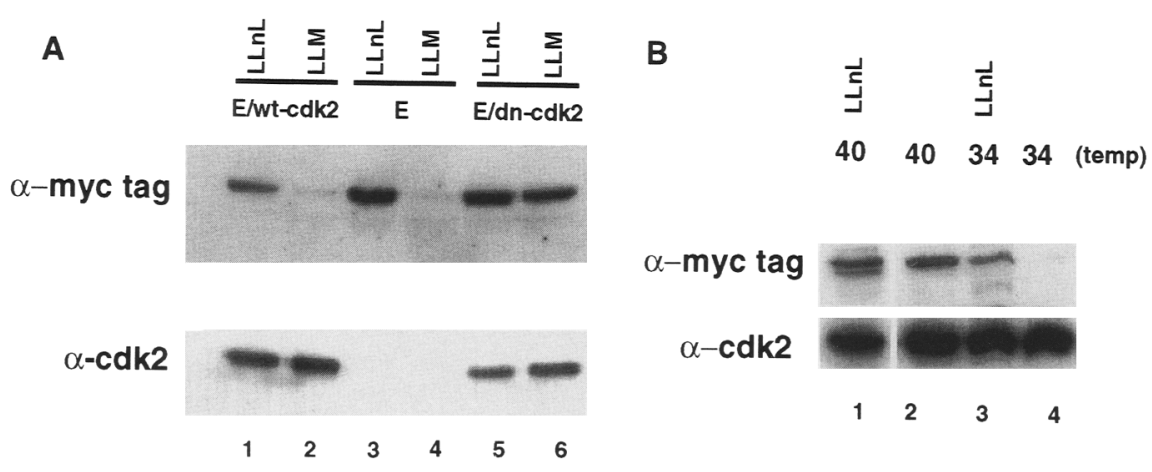


A

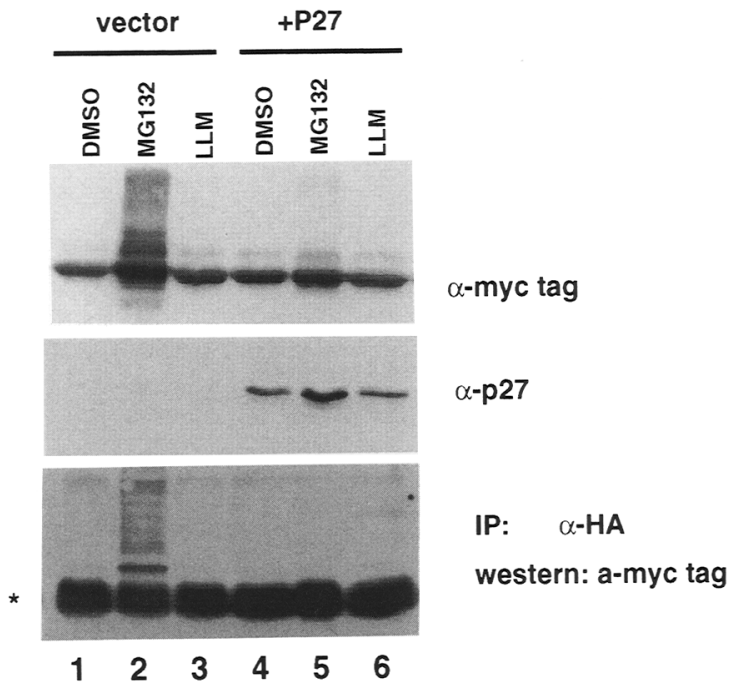

B

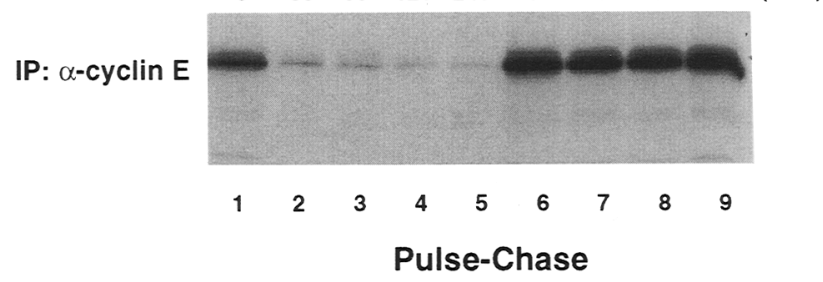

Figure 6. Expression of p27 inhibits the ubiquitination and degradation of cyclin E. (A) p27 overexpression blocks cyclin E ubiquitination. NIH-3T3 cells were cotransfected with m-cyclin E, HA-tagged ubiquitin, and either vector (lanes 1-3) or CS2p27 (lanes 4-6). Cells were then treated with either DMSO (lanes 1,4), or the peptide aldehydes MG132 (lanes 2,5), or LLM (lanes 3,6). (Bottom) The ladder of high molecular weight species is composed of cyclin E-ubiquitin conjugates. The IgG heavy chain is marked with an asterisk. $(B)$ p27 stabilizes cyclin E. NIH-3T3 cells were transfected with $\mathrm{m}$-cyclin $\mathrm{E}$ and either vector (lanes 1-5) or CS2p27 (lanes 6-9). Cells were then metabolically labeled and immunoprecipitated as described in the text.

precipitation-(IP)-Western analysis, and its formation was blocked by $\mathrm{p} 27$ expression, demonstrating that $\mathrm{p} 27$ inhibits the polyubiquitination of $\mathrm{m}$-cyclin $\mathrm{E}$. Because inhibition of cyclin $E$ ubiquitination should result in prolonging of its half-life, a pulse-chase analysis was performed in which cells were metabolically labeled with $\left[{ }^{35} \mathrm{~S}\right]$ methionine after transfection with $\mathrm{m}$-cyclin $\mathrm{E}$ and either $\mathrm{p} 27$ or vector (Fig. 6B). Expression of $\mathrm{p} 27$ prolonged the half-life of cyclin $\mathrm{E}$ from $<15 \mathrm{~min}$ to $>2 \mathrm{hr}$. Thus, the steady-state accumulation of cyclin $E$ induced by $\mathrm{p} 27$ expression results from inhibition of cyclin $\mathrm{E}$ ubiquitination and prevention of its degradation.

\section{Is the cyclin $E$ in complex with cdk2 ubiquitinated?}

As described above, cells transfected with $\mathrm{m}$-cyclin $\mathrm{E}$ and then treated with the proteasome inhibitor LLnL accumulated large amounts of multiubiquitinated cyclin E. However, little, if any, multiubiquitinated cyclin $\mathrm{E}$ appeared to be associated with cdk2. Lysates of cells transfected with $\mathrm{m}$-cyclin $\mathrm{E}$ were immunoprecipitated with antibodies directed against exogenous cyclin $\mathrm{E}(9 \mathrm{E} 10)$ or cdk2 (Fig. 7A). In cyclin E immunoprecipitates, both unconjugated and multiubiquitinated cyclin E were readily detected, and their relative abundance approximated that observed in the total lysate. In contrast, only unconjugated cyclin $\mathrm{E}$ was found in association with cdk2, even when the film was greatly overexposed to facilitate detection of low levels of multiubiquitinated cyclin E.

We attempted to increase the formation of ubiquitinated $\mathrm{m}$-cyclin $\mathrm{E}-\mathrm{wt}$-cdk 2 complexes by vastly overex- pressing both $\mathrm{m}$-cyclin E and wt-cdk2 (Fig. 7B). It is important to distinguish these experiments from those described above, in which cyclin E was expressed at much lower levels that more closely approximated the endogenous levels of cyclin E and cdk2. In these latter experiments, both cdk2 and cyclin $\mathrm{E}$ were greatly overexpressed in order to shift the equilibrium toward assembly of cyclin E-cdk2 complexes. Indeed, these conditions resulted in the assembly of the expected large amounts of catalytically active cyclin E-cdk2 complexes as determined both by the amount and phosphorylation state of cdk2 bound to cyclin $\mathrm{E}$, and by the H1 kinase activity of the cyclin E-cdk2 complexes (data not shown). Rather than promote formation of cyclin E-ubiquitin conjugates, however, these conditions inhibited $\mathrm{m}$-cyclin $\mathrm{E}$ ubiquitination and stabilized $\mathrm{m}$-cyclin $\mathrm{E}$. Thus, promotion of cyclin E-cdk2 complex formation tends to inhibit cyclin E turnover by the ubiquitin-proteasome pathway, a conclusion we arrived at previously by other means. Moreover, if $\mathrm{m}$-cyclin $\mathrm{E}$ was ubiquitinated while bound to catalytically active cdk2, these conditions should have increased the amount of $\mathrm{m}$-cyclin E-ubiquitin conjugates. Therefore, this experiment and our inability to detect ubiquitinated cyclin $\mathrm{E}$ bound to cdk2 also suggest either that multiubiquitination of cyclin $\mathrm{E}$ promotes its rapid disassociation from $\mathrm{cdk} 2$, or that cyclin $\mathrm{E}$ must disassociate from cdk2 to be ubiquitinated.

\section{Discussion}

Our results suggest that cyclin E can exist in both stable and unstable states in the cell, and that the stability of cyclin $\mathrm{E}$ is determined primarily by whether or not it is 
A

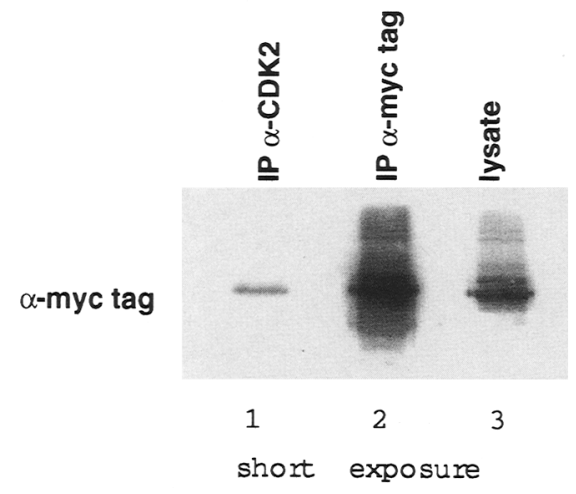

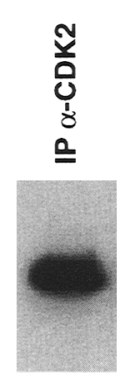

4

long exposure

B

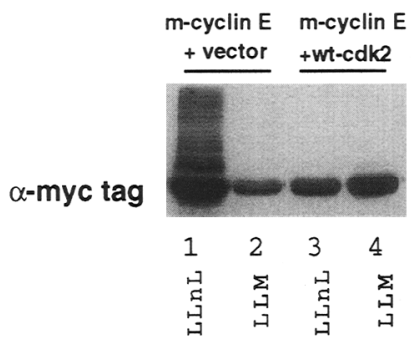

Figure 7. Ubiquitinated cyclin $\mathrm{E}$ is not found in complex with cdk2. (A) NIH-3T3 cells were transfected with $\mathrm{m}$-cyclin $\mathrm{E}$ and treated with LLnL for $12 \mathrm{hr}$. The cell lysate was then immunoprecipitated with antibodies directed against either the exogenous cyclin (lane 1) or endogenous cdk2 (lane 2). Cell lysate is shown in lane 3 for comparison. An overexposure of lane 1 is shown in lane 4 to emphasize that only unconjugated cyclin E coprecipitates with endogenous cdk2. $(B)$ Conditions favoring the formation of large amounts of catalytically active cyclin E-cdk2 complexes inhibit cyclin E ubiquitination. NIH-3T3 cells were transfected with m-cyclin E and either vector (lanes 1,2 ) or CMV-wt-cdk2 (lanes 3,4 ) under conditions promoting the assembly of large amounts of catalytically active cyclin E-cdk2 complexes, followed by treatment either LLnL (lanes 1,3) or LLM (lanes 2,4).

bound to cdk2. Free cyclin $\mathrm{E}$ (cyclin $\mathrm{E}$ not bound to $\mathrm{cdk} 2$ ) is an unstable protein whose turnover is controlled by the ubiquitin-proteasome pathway. In contrast, cyclin $\mathrm{E}$ within cyclin E-cdk2 complexes is protected from ubiquitin-dependent proteolysis. We have also shown that cyclin E can switch from being stable to unstable as a consequence of autophosphorylation within the cyclin E-cdk2 complex. In fact, our data imply that the major consequence of cyclin $\mathrm{E}$ phosphorylation may be to promote disassembly of the cyclin E-cdk2 complex. Once cyclin $\mathrm{E}$ becomes free of $\mathrm{cdk} 2$, it is ubiquitinated and degraded in the proteasome. Below, we discuss the evidence supporting each step in the pathway regulating cyclin $\mathrm{E}$ degradation.

Degradation of free cyclin $E$ by the ubiquitin-proteasome pathway

Several observations support the notion that free cyclin $E$ is readily ubiquitinated and its steady-state accumulation is proteasome dependent. First, we used experimental conditions in which the levels of overexpressed cyclin E exceed the available cdk2. Under these conditions, peptide aldehyde-mediated proteasome inhibition causes increased accumulation of both cyclin $\mathrm{E}$ and ubiquitincyclin E conjugates. Second, in cells expressing a cyclin $\mathrm{E}$ mutant deficient in cdk2 binding, proteasome inhibition causes a similar increase in the abundance of both cyclin $\mathrm{E}$ and ubiquitin-cyclin $\mathrm{E}$ conjugates. Third, when cyclin $\mathrm{E}$ is overexpressed in cells containing a thermolabile El, cyclin E ubiquitination and steady-state accumulation become temperature dependent. Thus, at the permissive temperature for $\mathrm{E} 1$ function, cyclin $\mathrm{E}$ accumulation increases only after treatment of the cells with a proteasome inhibitor, whereas at the nonpermissive temperature for E1, cyclin E accumulates to high levels without pharmacologic inhibition of the proteasome. Ubiquitination of free cyclin $\mathrm{E}$ may be one way to keep cyclin $\mathrm{E}$ expression in balance with $\mathrm{cdk} 2$, by promoting the destruction of excess cyclin.

\section{Association of cyclin $E$ with cdk2 inhibits cyclin $E$ ubiquitination}

In contrast to free cyclin E, cyclin E bound to catalytically inactive cdk2 accumulates to higher steady-state levels, and these levels are not further increased by inhibition of the proteasome. Also, proteasome inhibition leads to the accumulation of ubiquitin conjugates of free cyclin E, but not of cyclin E within these cyclin E-cdk2 complexes. How might complex formation with cdk2 prevent cyclin $\mathrm{E}$ ubiquitination? It is possible that binding to cdk2 alters the conformation of cyclin E so that it no longer is recognized by the ubiquitin-conjugating enzymes. However, at least for cyclin A, the structure of the cyclin is not significantly altered by binding to a cdk (Jefferey et al. 1995). Therefore, it seems more likely that binding of cyclin $\mathrm{E}$ to cdk2 might simply mask the motifs in cyclin E recognized by the E2 or E3 ubiquitinconjugating enzymes (or perhaps hide the ubiquitin attachment sites themselves). In either case, ubiquitination would be prevented until these motifs are unmasked by further modification of the cyclin-cdk complex.

At first glance, it might seem odd that the turnover of cyclin $\mathrm{E}$ is inhibited by its association with $\mathrm{cdk} 2$, whereas the turnover of cyclins $A$ and $B$ is promoted by cdk binding (Stewart et al. 1994; van der Velden et al. 1994). This may be a reflection of differences in how the sequences in cyclin $\mathrm{E}$ and the destruction box in cyclins $\mathrm{A}$ and $\mathrm{B}$ are recognized by ubiquitin-conjugating 
A

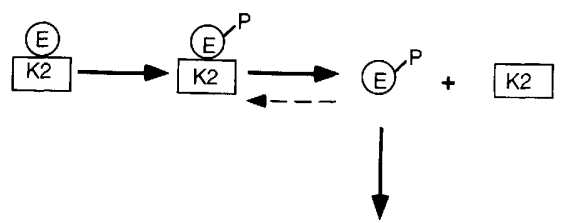

B

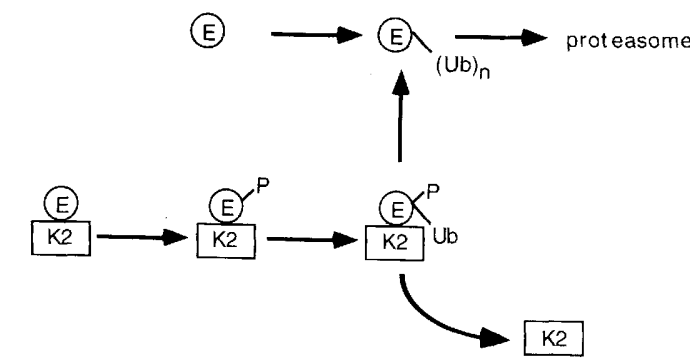

Figure 8. Alternate pathways for cyclin E degradation by the ubiquitin-proteasome system. The three routes discussed in the text by which cyclin $\mathrm{E}$ may be degraded are depicted. In pathway A, autophosphorylation of cyclin E promotes cyclin E-cdk2 disassembly, followed by ubiquitination of free cyclin $E$ via pathway $B$. The ubiquitination of cyclin $E$ in complex with cdk2 followed by rapid and irreversible complex disassembly is shown in pathway $\mathrm{C}$.

enzymes. In both cases, however, it is cdk catalytic activity that initiates cyclin degradation, and from this point of view, the regulation $\mathrm{G}_{1}$ and mitotic cyclin turnover is actually quite similar.

\section{Cyclin E phosphorylation promotes its ubiquitination}

Cyclin $\mathrm{E}$ is protected from ubiquitination by its assembly into catalytically inactive complexes with cdk2. This was shown by use of a cdk 2 mutant that cannot bind ATP, and by coexpression of wild-type cdk 2 with the cdk inhibitor $\mathrm{p} 27 \mathrm{Kip} 1$. In contrast, cyclin E ubiquitination is not significantly blocked by its assembly into catalytically active cyclin E-cdk2 complexes. Therefore, we conclude that the proteasomal degradation of cyclin $E$ bound to cdk 2 is regulated by cdk 2 catalytic activity.

One mechanism by which cdk2 activity affects cyclin E turnover appears to be by phosphorylation of cyclin $\mathrm{E}$ itself. This conclusion is derived from our observation that a cyclin E mutant in which the T380 phosphorylation site was changed to alanine is stabilized by binding to $\mathrm{cdk} 2$ regardless of whether the cdk2 is catalytically active or inactive. In contrast, the steady-state levels and ubiquitination of free cyclin $\mathrm{E}$ are not affected by the T380 mutation, implying that cyclin phosphorylation is only required for the ubiquitination and turnover of cyclin within cyclin-cdk complexes. Together, these data suggest that motifs required for cyclin $\mathrm{E}$ ubiquitination are hidden upon binding to $\mathrm{cdk} 2$, and phosphorylation of cyclin E unmasks these motifs. A similar model has recently been proposed for the $\operatorname{cln} 2$ protein, for which association with cdc 28 results in cln 2 autophosphorylation and instability (Lanker et al. 1996).
Phosphorylation-dependent disassembly of cyclin E-cdk2 complexes: A novel mechanism controlling cyclin stability?

There are a number of ways in which cyclin phosphorylation might promote its ubiquitination and proteasomedependent degradation. For example, phosphorylation might create or unmask a signal that is recognized by the E2 or E3 ubiquitin-conjugating enzymes, allowing ubiquitination and turnover of the cyclin E-cdk2 complex. However, this idea, in its simplest form, does not appear to be correct: We have been unable to detect ubiquitinated cyclin $\mathrm{E}$ in complex with cdk2, by use of assay conditions and sensitivities that should allow the detection of these complexes. Yet, experiments with E1 mutant cell lines and experiments with proteasome inhibitors both show that turnover of cyclin E within cyclin E-cdk2 complexes occurs by the ubiquitin-proteasome pathway. Alternative models consistent with these observations are (1) that ubiquitination of cyclin $\mathrm{E}$ in complex with cdk 2 causes the rapid and essentially irreversible disassembly of these complexes, or (2) that phosphorylation causes cyclin $\mathrm{E}$ to first disassociate from $\operatorname{cdk} 2$, and only then can it be ubiquitinated (Fig. 8).

The key difference between these models is that in the former model, cyclin $\mathrm{E}$ would be ubiquitinated while bound to cdk2, whereas in the latter model, it would need to disassociate first. Therefore, one way to distinguish between these possible pathways is to compare the extent of cyclin $\mathrm{E}$ ubiquitination under conditions that tend to favor cyclin E-cdk2 complex assembly (high concentration of cyclin $\mathrm{E}$ and $\mathrm{cdk} 2$ ) with conditions that tend to promote disassembly (low concentrations of both cyclin and cdk). This comparison was accomplished by use of transient transfection to increase the concentration of both wild-type-cyclin $\mathrm{E}$ and wild-type-cdk2 in the cell, thereby establishing conditions that favor the assembly of large amounts of catalytically active cyclin E-cdk2 complexes. We found that this overexpression inhibits, rather than promotes, cyclin E ubiquitination, showing that conditions that favor assembly of cyclin E-cdk2 complexes (even if they are catalytically active) are inhibitory for cyclin $\mathrm{E}$ ubiquitination. These results support the idea that cyclin $\mathrm{E}$ must dissociate from cdk2 prior to ubiquitination, and are not consistent with a model in which cyclin $\mathrm{E}$ is ubiquitinated within catalytically active cyclin E-cdk2 complexes. To explain the linkage between cyclin $\mathrm{E}$ phosphorylation and ubiquitination, we suggest that phosphorylation may promote the disassociation of cyclin $\mathrm{E}$ from $\mathrm{cdk} 2$. If disassociation of cyclin $\mathrm{E}$ from cdk2 occurred as a direct consequence of phosphorylation, then the phosphorylation of other substrates by cyclin E-cdk2 would be limited by the relative kinetics of auto- versus trans-phosphorylation. It seems more likely that autophosphorylation is necessary, but insufficient for cyclin $\mathrm{E}$ degradation, and that additional events are required prior to cyclin $\mathrm{E}$ ubiquitination. For instance, phosphorylated cyclin $\mathrm{E}$ might be recognized by another protein that would then catalyze disassembly of the cyclin-cdk complex. A requirement for additional 
events after cyclin E phosphorylation interposes an additional layer of control on cyclin degradation. This could be used to couple cyclin $\mathrm{E}$ inactivation to the successful execution of specific cell-cycle functions.

There are several possible advantages of cyclin E-cdk2 disassembly prior to ubiquitination. Because cyclins may determine the substrate specificity of associated kinase subunits, ubiquitinated cyclin $\mathrm{E}$ that remains associated with active cdk2 might result in aberrant substrate selection. Similarly, ubiquitinated cyclin $\mathrm{E}$ in complex with cdk2 might cause the subcellular mislocalization of active cyclin E-cdk-2 complexes, perhaps as a result of the ubiquitin moieties directing the active E-cdk2 complex to the cytoplasm. Again, the result might be inappropriate substrate selection. In addition, a prerequisite for cyclin E-cdk2 disassociation also provides an additional level of control by which cyclin $\mathrm{E}$ degradation may be regulated.

In conclusion, cdk2 activity has opposing effects on the abundance of cyclin $\mathrm{E}$ protein. On the one hand, transcription of the cyclin E gene is induced by E2F (DeGregori et al. 1995; Geng et al. 1996). Therefore, cdk activation will increase cyclin $\mathrm{E}$ gene expression via phosphorylation of $\mathrm{Rb}$ and liberation of E2F. On the other hand, cdk2 also phosphorylates cyclin E, and our results show that this initiates the process of cyclin $E$ proteolytic degradation. In this study we expressed cyclin E from a constitutively active, E2F-independent promoter, and this enabled us to isolate the regulation of cyclin E proteolytic degradation from its transcriptional regulation. However, when linked together in series, the transcription and proteolytic pathways are likely to produce a burst of cyclin E expression followed by elimination of active cyclin $E$ by the proteosome. This may generate the pulse of cyclin E-cdk2 activity observed as cells transit $G_{1}$ and enter $S$ phase (Dulic et al. 1992; Koff et al. 1992). Conversely, agents or signals which inhibit cdk activity will decrease cyclin $\mathrm{E}$ gene expression, but will also increase stability of the cyclin $E$ protein. Thus, there will be little net effect on the steady-state abundance of the cyclin E protein, at least in the short term, and this will enable the cell to resume cell cycle progression once the inhibitory signals are withdrawn.

\section{Materials and methods}

Cell cultures, plasmids, and transfections

NIH-3T3 cells were obtained from C. Sherr /St. Judes, Memphis $\mathrm{TN}$ ) and grown in Dulbecco's modified Eagle medium (DMEM) supplemented with $10 \%$ fetal bovine serum (FBS, Hyclone) at $37^{\circ} \mathrm{C} / 5 \% \mathrm{CO}_{2}$. E36 and E36ts20 cells were a gift from S. Handelli [Fred Hutchinson Cancer Research Center (FHCRC), Seattle, WA] and grown in DMEM $/ 10 \%$ FBS at either $34^{\circ} \mathrm{C}$ or $39.5^{\circ} \mathrm{C} / 5 \% \mathrm{CO}_{2}$. TS20 cells were shifted to the nonpermissive temperature for $12 \mathrm{hr}$ prior to lysis. Cells were transfected in 60-mm dishes by the calcium phosphate method as follows: Plasmid DNAs were suspended in $0.25 \mathrm{cc} 122 \mathrm{mM} \mathrm{CaCl}$ and added dropwise to $0.25 \mathrm{cc}$ of $2 \times$ HEPES-buffered saline, mixed once, and immediately added dropwise to plates. For conditions favoring free cyclin E, $1.5 \mu \mathrm{g}$ of cyclin plasmid was used per dish. For conditions favoring complex formation, $300 \mathrm{ng}$ of cyclin plasmid and $3 \mu \mathrm{g}$ of cdk2 plasmid were cotransfected per dish. CMV-HA-ubiquitin was included in transfection mixes to facilitate detection of ubiquitin conjugates. Total DNA concentrations per dish were fixed at $6 \mu \mathrm{g} / 60 \mathrm{~mm}$ dish by addition of empty vectors to transfections such that the amount of various expression vectors was normalized to control for promoter competition effects. Transfection efficiency was monitored by use of $250 \mathrm{ng}$ of CMV- $\beta$ gal plasmid per transfection, and colorimetric $\beta$-gal assays were performed by standard methods (Sambrook et al. 1989).

The following plasmids were used for transfections: pCS2 $\mathrm{m}$-cyclin $\mathrm{E}$ was constructed by ligation of the carboxyl terminus of the human cyclin E gene contained on a 500-bp SacI-ApaI fragment from pCS2Hu4 (M. Ohtsubo, FHCRC) into pCS2MTE (B. Kelley, FHCRC) that had been cut with SacI-ApaI, pCS2 $\mathrm{m}$-cyclin $\mathrm{E}(\mathrm{R} 130 \mathrm{~A})$ was constructed analogously by ligation of the 500-bp SacI-ApaICS2Hu4 fragment into pCS2NBCE, which contains the R130A mutation (J. Swanger, FHCRC); pCMVHis $_{6}$ ubi and pHA-ubi (M. Treier, EMBL, Heidelberg, Germany); p-CMV-cdk2wt and pCMV-cdk2D145N (S. van den Heuval and E. Harlow, Massachusetts General Hospital, Charlestown); pCS2p27 (M. Ohtsubo); pCMVp21, pCMVp27, pCMVp27(1-86), and pMVp27(87-278) (J. Massague, Sloan-Kettering, New York); pCMVp16 (E. Harlow); CMV-ßgal (A. Geballe, FHCRC); pCS2 m-cyclin A was constructed by ligation of the excised $\mathrm{Ncol}-$ BamHI fragment containing the human cyclin A gene from pNAl (E. Lees, DNAX, Palo Alto, CA) into pCS2MT (D. Turner, FHCRC) that had been cut with XhoI after both DNA fragments had been treated with Klenow enzyme to generate blunt ends. The cyclin E cdk phosphorylation site mutants (Epl-Ep5) were generated from pCS2 $\mathrm{m}$-cyclin $\mathrm{E}$ by converting the serine or threonine residues indicated in the text to alanines by site directed mutagenesis of single-stranded template DNA by standard methods (Kunkel et al. 1987).

Western blotting analysis, immunoprecipitation, and cyclin kinase assays

Cells were lysed directly on $60-\mathrm{mm}$ tissue culture dishes in RIPA buffer containing protease and phosphatase inhibitors $\{10$ mM Tris at $\mathrm{pH} 7.4,0.15 \mathrm{M} \mathrm{NaCl}, 1 \% \mathrm{NP}-40,1 \%$ deoxycholate, $0.1 \%$ SDS $10 \mu \mathrm{g} / \mathrm{ml}$ each of aprotonin, leupeptin, and pepstatin, $50 \mathrm{~mm} \mathrm{NaF}, 1 \mathrm{~mm} \mathrm{Na}$ vanadate), followed by scraping and sonication. After protein quantification and normalization, cell extracts were electrophoresed on $12 \%$ polyacrylamide gels and transferred to PVDF membranes as described previously (Amersham) (Koff et al. 1992; Ohtsubo and Roberts 1993). After incubation with primary antibodies (see below), proteins were visualized by incubation with HRP-conjugated anti-rabbit or anti-mouse secondary antibodies as appropriate (Amersham), followed by ECL per the manufacturer's instructions (Amersham).

Immunoprecipitation was performed as follows: 100-200 $\mu \mathrm{l}$ of cell lysates normalized for protein concentration were incubated at $4^{\circ} \mathrm{C}$ for $1 \mathrm{hr}$ with appropriate dilutions of primary antibodies and $30 \mu l$ of either Gammabind Plus Sepharose (Amersham) or protein A-Sepharose (Sigma) for monoclonal mouse primary antibodies and rabbit primary antisera, respectively. Precipitates were washed five times with $1 \mathrm{ml}$ of RIPA buffer before electrophoresis and Western transfer. Histone Hl kinase assays were performed a previously described (Koff et al. 1992). Autophosphorylation assays were done as $\mathrm{HHl}$ kinase assays except that cold ATP and histone $\mathrm{H} 1$ were omitted from the reaction. 


\section{Antibodies}

9 E10 (anti-myc tag) was prepared by an in-house biologic production facility; $\alpha$-p27, and $\alpha$-cyclin $\mathrm{E}$ have been previously described (Koff et al. 1992; Coats et al. 1996) $\alpha$-cdk2 (M2), $\alpha$-p21 and $\alpha$-p 16 were obtained from Santa Cruz; $\alpha$-HA was a gift from S. Coats (FHCRC).

\section{Proteasome inhibitors and detection of ubiquitin-cyclin $E$ conjugates}

LLnL and LLM were obtained from Sigma and dissolved at 20 mM in DMSO. MG-132 was a gift from M. Horowitz (University of Washington, Seattle). Approximately $24 \mathrm{hr}$ after transfection, cells were treated with peptide aldehydes overnight (LLnL and LLM at $50 \mu \mathrm{M}, \mathrm{MG}-132$ at $2 \mu \mathrm{M})$. Cells were lysed as above with the addition of $5 \mathrm{mM}$ NEM (Sigma) to the lysis buffer. The immunoprecipation-Western analysis for the detection of HAtagged ubiquitin-cyclin $\mathbf{E}$ conjugates was essentially as described by Treier et al. (1994). Cells growing on 60-mm dishes were cotransfected with cyclin $\mathrm{E}$ and either $\mathrm{HA}$ or $\mathrm{His}_{6}$ tagged ubiquitin expression plasmids, followed by peptide aldehyde treatment, lysis, and immunoprecipitation as described in the text.

\section{Metabolic labeling and pulse-chase analysis}

Cells were seeded onto $150-\mathrm{mm}$ dishes and transfected as above except that $2 \mathrm{ml}$ of transfection mix was used per plate. Approximately $36 \mathrm{hr}$ after transfection, the plates were washed with PBS, and incubated in DMEM without methionine/cysteine (ICN) for $15 \mathrm{~min}$. Trans ${ }^{35} \mathrm{~S}$-label (ICN) was then added to a final concentration of $200 \mu \mathrm{Ci} / \mathrm{ml}$ and the cells labeled for 30 min at $37^{\circ} \mathrm{C}$. The plates were then washed and chased with DMEM/10\% FBS supplemented with $150 \mathrm{mg} /$ liter cold methionine. Cells were scraped from sectors of the plates, lysed as above at the indicated time points, and the cleared lysates immunoprecipitated after normalization. After electrophoresis, the gel was fixed, soaked in Amplify (Amersham), and fluorographed according to the manufacturer's instructions.

\section{Cell-cycle analysis}

Dishes $(100 \mathrm{~mm})$ were seeded with NIH-3T3 cells and transfected with $10 \mu \mathrm{g}$ of cyclin E plasmid and $5 \mu \mathrm{g}$ of CMV-CD20 per plate. Cells were then stained with $\alpha$-CD20 antibody (Becton-Dickinson) and propidium iodide as described (van den Heuval 1993). Cells were analyzed on a FACSCAN II followed by data analysis with MultiCycle.

\section{Acknowledgments}

We thank S. Reed for communicating results prior to publication. This work was supported by National Institute of Health grants CA64216 to B.E.C., and CA54337 to M.G.; B.E.C. is supported by the Jose Carerras Leukemia Foundation; R.J.S. is supported by the Cancer Research Fund of the Damon RunyonWalter Winchell Foundation fellowship DRG-1313.

The publication costs of this article were defrayed in part by payment of page charges. This article must therefore be hereby marked "advertisement" in accordance with 18 USC section 1734 solely to indicate this fact.

\section{References}

Barral, Y., S. Jentsch, and C. Mann. 1995. G $_{1}$ cyclin turnover and nutrient uptake are controlled by a common pathway in yeast. Genes \& Dev. 9: 399-409.

Chen, Z., J. Hagler, V. Palombella, F. Melandri, D. Scherer, D. Ballard, and T. Maniatis. Signal-induced site-specific phosphorylation targets $I_{\kappa} B \alpha$ to the ubiquitin-proteasome pathway. 1995. Genes \& Dev. 9: 1586-1597.

Ciechanover, A. 1994. The ubiquitin-proteasome proteolytic pathway. Cell 79: 13-21.

Coats, S., M. Flanagan, J. Nourse, and J. Roberts. 1996. Requirement of $\mathrm{p} 27 \mathrm{kip} 1$ for restriction point control of the fibroblast cell cycle. Science 272: 877-880.

Cross, F. and C. Blake. 1993. The yeast cln3 protein is an unstable activator of cdc28. Mol. Cell. Biol. 13: 3266-3271.

DeGregori, J., T. Kowalik, and J.R. Nevins. 1995. Cellular targets for activation by the E2F1 transcription factor include DNA synthesis- and G1/S-regulatory genes. Mol. Cell. Biol. 15: 4215-4224.

Deshaies, R. 1995. Make it or break it: The role of ubiquitindependent proteolyisis in cellular regulation. Trends Cell Biol. 5: 428-434.

Deshaies, R., V. Chau, and M. Kirschner. 1995. Ubiquitination of the G1 cyclin $C \ln 2 p$ by a cdc34p-dependent pathway. EMBO J. 14: 303-312.

Dulic, V., E. Lees, and S. Reed. 1992. Association of human cyclin E with a periodic Gl-S phase protein kinase. Science 257: 1958-1961.

Duronio, R. and P. O'Farrell. 1995. Developmental control of the $\mathrm{G} 1$ to $\mathrm{S}$ transition in Drosophila: Cyclin E is a limiting downstream target of E2F. 1995. Genes \& Dev. 9: 1456-1468

Geng, Y., E. Eaton, M. Picon, J. Roberts, A. Lundberg, A. Gifford, C. Sardet, and R. Weinberg. 1996. Regulation of cyclin E transcription by E2Fs and retinoblastoma protein. Oncogene 12: 1173-1179.

Glotzer, M., A. Murray, and M. Kirschner. 1991. Cyclin is degraded by the ubiquitin pathway. Nature 349: 132-138.

Hochstrasser, M. 1995. Ubiquitin, proteasomes, and the regulation of intracellular protein degradation. Curr. Opin. Cell Biol. 7: 215-223.

Jeffrey, P., A. Russo, K. Polyak, E. Gibbs, J. Hurwitz, J. Massague, and N. Pavletich. 1995. Mechanism of CDK activation revealed by the structure of a cyclinA-CDK2 complex. Nature 376: 313-320.

Jentsch, S. and S. Schlenker. 1995. Selective protein degradation: A journey's end within the proteasome. Cell 82: 881884.

King, R., J. Peters, S. Tugendreich, M. Rolfe, P. Hieter, and M. Kirschener. 1995. A 20 S complex containing cdc27 and cdc16 catalyzes the mitosis-specific conjugation of ubiquitin to cyclin B. Cell 81: 279-288.

Kobayashi, H., E. Stewart, R. Poon, J. Adamczewski, J. Gannon, and T. Hunt. 1992. Identification of the domains in cyclin A required for binding to, and activation of p34cdc2 and p32cdk2 protein kinase subunits. Mol. Biol. Cell 3: 12791294.

Koff, A., F. Cross, A. Fisher, J. Schumacher, K. Leguellec, M. Philippe, and J.M. Roberts. 1991. Human cyclin E, a new cyclin that interacts with two members of the CDC2 gene family. Cell 66: 1217-1228.

Koff, A., A. Giordano, D. Desai, K. Yamashita, J.W. Harper, S. Elledge, T. Nishimoto, D. Morgon, B.R. Franza, and J.M. Roberts. 1992. Formation and activation of a cyclin E-cdk2 complex during the Gl phase of the human cell cycle. Science 257: 1689-1693. 
Kulka, R., B. Raboy, R. Schuster, H. Parag, G. Diamond, A. Ciechanover, and M. Marcus. 1988. A Chinese hamster cell cycle mutant arrested at G2 phase has a temperature-sensitive ubiquitin-activating enzyme, E1. I. Biol. Chem. 263: 15726-15731.

Kunkel, T. A., J. Roberts, and R. Zakour. 1987. Rapid and efficient site-specific mutagenesis without phenotypic selection. Meth. Enzymol. 154: 367-382.

Lanker, S., M. Valdivieso, and C. Wittenberg. 1996. Rapid degradation of the $\mathrm{G} 1$ cyclin cln 2 induced by CDK-dependent phosphorylation. 1996. Science 271: 1597-1601.

Lew, D.J., V. Dulic, and S.I. Reed. 1991. Isolation of three novel human cyclins by rescue of $\mathrm{Gl}$ cyclin $(\mathrm{Cln})$ function in yeast. Cell 66: 1197-1206.

Nasmyth, K. and L. Dirick. 1991. The role of SW14 and SW16 in the activity of G1 cyclins in yeast. Cell 66: 995-1013.

Ogas, J., B.J. Andrews, and I. Herskowitz. 1991. Transcriptional activation of CLN1, CLN2, and a putative new Gl cyclin by SWI4, a positive regulator of G1-specific transcription. Cell 66: $1015-1026$.

Ohtsubo, M. and J. Roberts. 1993. Cyclin-dependent regulation of G1 in mammalian fibroblasts. Science 259: 1908-1912.

Ohtsubo, M., A.M. Theodoras, J. Schumacher, J.M. Roberts, and M. Pagano. 1995. Human cyclin E, a nuclear protein essential for the Gl to $\mathrm{S}$ phase transition. Mol. Cell. Biol. 15(5): 2612-2624.

Polyak, K., M. Lee, H. Erdjument-Bromage, A. Koff, J. Roberts, P. Tempst, and J. Massague. 1994. Cloning of p27Kipl, a cyclin-dependent kinase inhibitor and a potential mediator of extracellular antimitogenic signals. Cell 78: 59-66.

Resnitzky, D., M. Gossen, H. Bujard, and S. Reed. 1994. Acceleration of the Gl/S phase transition by expression of cyclins $\mathrm{Dl}$ and $\mathrm{E}$ with an inducible system. Mol. Cell. Biol. 14: 1669-1679.

Rock. K., C. Gram, L. Rothstein, K. Clark, R. Stein, L. Dick, D. Hwang, and A. Goldberg. 1994. Inhibitors of the proteasome block the degradation of most cell proteins and the generation of peptides presented on MHC class I molecules. Cell 78: 761-771.

Rogers, S., R. Wells, and M. Rechsreiner. 1986. Amino acid sequences common to rapidly degraded proteins: The PEST hypothesis. Science 234: 364-368.

Sambrook, J., E. Fritsch, and T. Maniatis. 1989. Assay for $\beta$-galactosidase in extracts of mammalian cells. In Molecular Cloning, pp. 16.66-16.67. Cold Spring Harbor Laboratory Press, Cold Spring Harbor, NY.

Schneider, B., Y. Yang, and B. Futcher. 1996. Linkage of replication to start by the CDK inhibitor sicl. Science 272: 560562.

Sherr, C. 1994. Gl phase progression: Cycling on cue. Cell 79: 551-555.

Sherr, C. and J. Roberts. 1995. Inhibitors of mammalian $\mathrm{G}_{1}$ cyclin-dependent kinases. Genes \& Dev. 9: 1149-1163.

Stewart, E., H. Kobayashi, D. Harrison, and T. Hunt. 1994. Destruction of Xenopus cyclins $A$ and $B 2$, but not $B 1$, requires binding to p34cdc2. EMBO /. 13: 584-594.

Sudakin, V., D. Ganoth, A. Dahan, H. Heller, J. Hershko F. Luca, J. Ruderman, and A. Hershko. 1995. The cyclosome, a large complex containing cyclin-selective ubiquitin ligase activity, targets cyclins for destruction at the end of mitosis. Mol. Biol. Cell 6: 185-197.

Treier, M., L. Staszewski, and D. Bohmann. 1994. Ubiquitindependent c-Jun degradation in vivo is mediated by the $\gamma$ domain. Cell 78: 787-798.

Tyers, M., G. Tokiwa, R. Nash, and B. Futcher. 1992. The cln2cdc 28 kinase complex of $\mathrm{S}$. cerevisiae is regulated by prote- olysis and phosphorylation. EMBO J. 11: 1773-1784.

van den Heuval, S. and E. Harlow. 1993. Distinct roles for cyclin-dependent kinases in cell cycle control. Science 262: 2050-2054.

van der Velden, H. and V. Lohka. 1994. Cell cycle-regulated degradation of xenopus cyclin $\mathrm{B} 2$ requires binding to p34cdc2. Mol. Cell. Biol. 5: 713-724.

Won, K. and S. Reed. 1996. Activation of cyclin E/cdk2 is coupled to site-specific autophosphorylation and ubiquitin-dependent degradation of cyclin E. EMBO J. 15 (in press).

Yaglom, J., M. Linskens, S. Sadis, D. Rubin, B. Futcher, and D. Finley. 1995. p34 ${ }^{\mathrm{Cdc} 28}$-mediated control of cln3 degradation. Mol. Cell. Biol. 15: 731-741. 


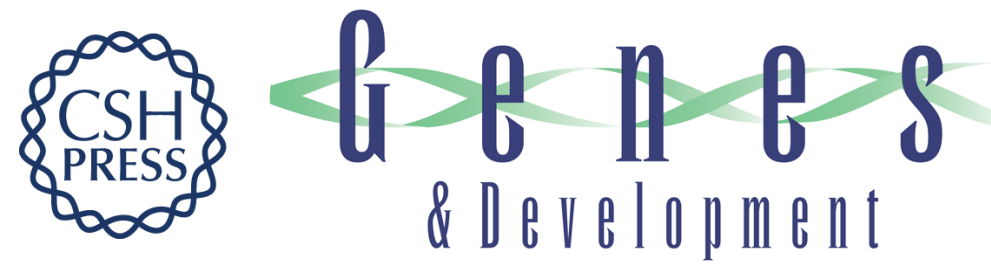

\section{Turnover of cyclin E by the ubiquitin-proteasome pathway is regulated by cdk2 binding and cyclin phosphorylation.}

B E Clurman, R J Sheaff, K Thress, et al.

Genes Dev. 1996, 10:

Access the most recent version at doi:10.1101/gad.10.16.1979

References This article cites 41 articles, 19 of which can be accessed free at:

http://genesdev.cshlp.org/content/10/16/1979.full.html\#ref-list-1

License

Email Alerting

Service

Receive free email alerts when new articles cite this article - sign up in the box at the top right corner of the article or click here.

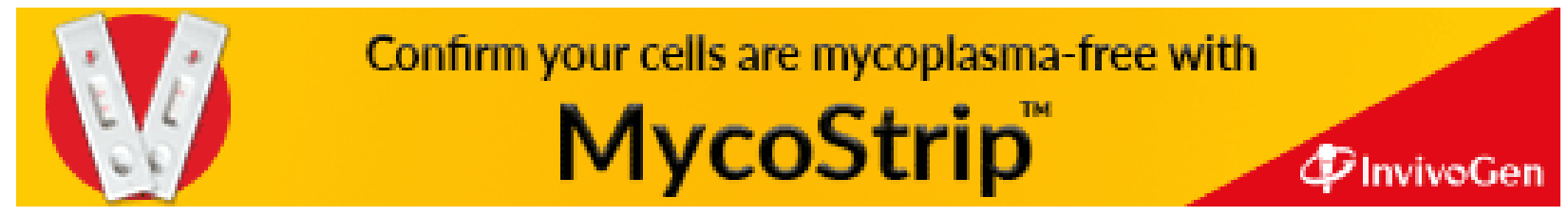

